\title{
Exposures to Violence and Trauma among Children and Adolescents in Our Global Society
}

\author{
Clarissa Agee Shavers \\ The Safer Tomorrows: Injury Prevention and Violence Reduction Project ${ }^{\odot}$, Primary Care Office, \\ Detroit, USA \\ Email: ageeclar@gmail.com
}

Received July $1^{\text {st }}, 2012$; revised November $6^{\text {th }}, 2012$; accepted December $12^{\text {th }}, 2012$

\begin{abstract}
Globally, hundreds of children and adolescents witness acts of violence and trauma on a daily basis. Notably, children and adolescents exposed to violence and trauma may display mild-to-severe psycho-socialemotional and mental health care problems. Also, exposures to violence and trauma among children and adolescents have resulted into an alarming global health care issue for our society. All health care providers (HCP's) must continue to actively engage in early identification, screening, assessing, and treating children and adolescents who self-disclose exposures to violence and trauma.
\end{abstract}

Keywords: Children; Adolescents; Violence; Trauma; Health Care Providers

Exposures to various forms of violence including homicide and trauma among children and adolescents (youth) have resulted in a significant burden on our global society (Shavers, 2009; Pinheiro, 2006; Fraser, 2012). Similarly, these reported occurrences of exposures to violence and trauma among children and youth remains to be an escalating or spiraling global public health concern (Shavers, 2010). On a global scale, investigators have reported that thousands of youth report witnessing or experiencing various acts related to violence and trauma on a daily basis (Vernberg, Nelson, Fonagy, \& Twemlow, 2011; Children's Defense Fund, 2012; World Health Organization, 2009). In fact, according to the aforementioned reports, globally, mortality and morbidity rates associated with exposures to violence and trauma among children and youth have resulted in a growing serious public health concern.

In addition, many investigators have denoted that with the ongoing prevalence and incidence of exposures to various forms of violence and trauma among children and youth may result in serious threats to their overall psycho-social-emotional, mental, and physical health including adverse long-term or chronic effects (Cisler, Amstadter, \& Nugent, 2011; Nader, 2011; Penn State, 2012; Felitti et al., 1998). Likewise, research has shown that children and youth who self-disclose exposures to violence and trauma either directly or as witnesses may be at-risk for experiencing psycho-social-emotional and mental health care issues including post-traumatic stress disorder (PTSD) or post-traumatic stress symptomatology (Cook et al., 2007; Shavers et al., 2005a; Task Force on Community Preventive Services, 2008). Also, even more devastating is the fact that the emotional trauma that may occur after a traumatic or violent injury may place the survivor (i.e. child or youth) at an increased risk for future injury, substance abuse and subsequently death (Finkelhor et al., 2009). Further, studies have reported that childhood or adolescent exposure to violence, victimization (i.e. bullying) and traumatic events have been associated with suicidal ideation among children and youth (Klomek, Sourander, \& Gould, 2012; Turner et al., 2012).
Similarly, evidence suggests that children and youth exposed to witnessing of violent and traumatic events in the home including Domestic Violence (DV) or Intimate Partner Violence (IPV) and/or in the community may also experience psychosocial-emotional, mental, and physical symptomatology (Holt, Buckley, \& Whelan, 2008; McDonald \& Richmond, 2008; Jaycox et al., 2010). Moreover, children and youth of battered or abused women have been noted to be significantly impacted by exposure to episodes of violence and trauma in the home (Shavers et al., 2005b). For much of the noted research reported has identified that witnessing violence and trauma (i.e. DV or IPV or Family Violence) in the home by children and youth may significantly impact their overall psycho-social- emotional health including their memory of these events or experiences (Shavers et al., 2005b; Cloitre et al., 2010). Further, the findings from the literature has also identified that children and youth witnessing violence or trauma in the home or other traumatic interpersonal events have been found to manifest symptoms of depression which may lead them to experience suicidal ideologies, cognitive deficits in attention and memory, anxiety and sleep disorders, aggression and feelings of sadness, loss, and anger (Cohen \& Walthall, 2003; Schwarz, 2009; Fletcher, 2011).

While not all children and youth who self-report exposures to violence and trauma may need health care intervention to effectively deal with the aftermath of victimization or traumatization, there are still a number of children and youth who will need to receive appropriate health care intervention to help them heal from such events. Thus, Health Care Providers (HCP's) are in a unique position to play a significant role in reducing the incidence of violence, violent-related injuries or acts and adverse traumatic events among this population. Similarly, not all children or youth may self-disclose exposures to violence and trauma for various reasons including fear (Shavers et al., 2005b). Therefore, it is utmost importance that HCP's be actively involved in measures that will allow early detection, intervention, and treatment as indicated. 
Likewise, HCP's should be aware of the fact that exposures to various forms of violence and trauma occur among children and youth from all socioeconomic, ethnic, religious and cultural backgrounds (Shavers, 2009). Furthermore, HCP's should know and understand the ethnic and cultural attitudes, feelings, values, beliefs, and behaviors in response to reported exposures to various forms of violence and trauma among children and youth in the communities that they serve or provide health care in order to be effective in meeting the needs of their patients or clients and in an effort to be culturally sensitive. Equally, HCP's should be cognizant of the fact that exposures to violence or acts related to violence and trauma among children and youth are common health care problems and concerns. In addition, HCP's should recognize that exposures to violence and trauma among children and youth may pose as risk factors for psycho-social-emotional, mental, and physical health care problems.

Further, HCP's are in a key position to screen, recognize, and assess for exposures to violence and trauma among children, youth, and their families. Also, HCP's need to provide and have readily available a variety of resources including communitybased, as well as, evidence-based resources that will promote a sense of health, safety and security, support, and advocacy for children and youth who disclose or are at-risk for exposures to violence and trauma. In the same way, HCP's need to know the local or governmental existing laws and procedures for reporting to respective authorities' children and youth who self-report or are at-risk for exposure to violence and trauma to ensure their safety. Finally, HCP's should work towards empowering children and youth to effectively address the issues of violence and trauma in their young lives.

So in summary, forlornly, exposures to various forms of violence and trauma among today's children and youth have been noted to be a serious threat to their psycho-social-emotional, mental, and overall physical health and wellbeing. Similarly, exposures to various forms of violence and trauma among today's children and youth cross all socioeconomic statuses, religious, ethnic-cultural, and geographical milieu (Shavers, 2009). Hence, HCP's should be cognizant of the fact that voluntarily or non-voluntarily self-reports of exposures to various forms of violence and trauma among children and youth are inevitable. Therefore, it is absolutely imperative that HCP's routinely screen, early identify, assess, and appropriately treat those children and youth who self-report exposures to violence and trauma in an effort to possibly circumvent or alleviate the previously noted adverse psycho-social-emotional, mental health and physical consequences.

Thus, in conclusion, it is of essence that HCP's should be cognizant of the actual, probable or potential detrimental impact of exposures to various forms of violence and trauma among children and youth in our global society. Moreover, HCP's are called to be proactively involved in all endeavors to promote the psycho-social-emotional, mental, physical and overall well-being of children and youth who disclose actual, previous or past, and probable or potential exposures to various forms of violence and trauma in our global society. This may be accomplished by HCP's incorporating routine screening, early identification, assessment, and appropriate therapeutic treatment modalities. Finally, one must remember that the future rests with our children and youth and therefore, the best approach on their behalf should be health promotion and prevention of exposures to violence and adverse traumatic events.

\section{Acknowledgements}

This article was supported by an academic publication grant from the Text and Academic Authors Association Inc. (TAA) URL:

http://www.taaonline.net/membersonly/publication_grants/inde x.html. Also, the author would like to acknowledge the following members of The Safer Tomorrows Project Research Team ${ }^{\circledR}$ : C.A. Archer-Gift, Ph.D., L.M. Green, M.A., L.L.P.C., B.S.W., J.E. Onyskiw, Ph. D. and M. Price, Ph.D. for their assistance and dedication to our mission and vision.

\section{REFERENCES}

Children's Defense Fund (2012). Protect children, not guns 2012. Washington, DC: Children's Defense Fund.

Cisler, J. M., Amstadter, A. B., \& Nugent, N. R. (2011). Genetic and environmental influences on posttrauma adjustment in children and adolescents: The role of personality constructs. Journal of Child \& Adolescent Trauma, 4, 301-317. doi:10.1080/19361521.2011.609154

Cloitre, M., Stovall-McClough, K. C., Nooner, K., Zorbas, P., Cherry, S., Jackson, C. L. et al. (2010). Treatment for PTSD related to childhood abuse: A randomized controlled trial. American Journal of Psychiatry, 167, 915-924. doi:10.1176/appi.ajp.2010.09081247

Cohen, E., \& Walthall, B. (2003). Silent realities: Supporting young children and their families who experience violence. Washington, DC: National Child Welfare Resource Center for Family-Centered Practice.

Cook, A., Spinazzola, J., Ford, J., Lanktree, C., Blaustein, M., \& Sprague, C. (2007). Complex trauma in children and adolescents. Focal Point, 21, 4-8.

Felitti, V., Anda, R., Nordenberg, D., Williamson, D., Spitz, A., Edwards, V. et al. (1998). Relationship of childhood abuse and household dysfunction to many of the leading causes of death in adults: The adverse childhood experiences (ACE) study. American Journal of Preventive Medicine, 14, 245-257. doi:10.1016/S0749-3797(98)00017-8

Finkelhor, D., Turner, H., Ormrod, R., Hamby, S., \& Kracke, K. (2009). Children's exposure to violence: A comprehensive national survey. Washington, DC: US Department of Justice, Office of Justice Programs, Office of Juvenile Justice and Delinquency Prevention.

Fletcher, K. E. (2011). Understanding and assessing traumatic responses of guilt, shame, and anger among children, adolescents, and young adults. Journal of Child \& Adolescent Trauma, 4, 339-360. doi:10.1080/19361521.2011.623146

Fraser, B. (2012). (World Report). Latin America looks to violence prevention for answers. The Lancet, 380 (9850), 1297-1298. doi:10.1016/S0140-6736(12)61745-0

Holt, S., Buckley, H., \& Whelan, S. (2008). The impact of exposure to domestic violence on children and young people: A review of the literature. Child Abuse \& Neglect, 32, 797-810. doi:10.1016/j.chiabu.2008.02.004

Jaycox, L. H., Cohen, J. A., Mannarino, A. P., Walker, D. W., Langley, A. K., Gegenheimer, K. L. et al. (2010). Children's mental health care following hurricane Katrina: A field trial of trauma-focused psychotherapies. Journal of Traumatic Stress, 23, 223-231.

Macdonald, C. C., \& Richmond, T. R. (2008). The relationship between community violence exposure and mental health symptoms in urban adolescents. Journal of Psychiatric Mental Health Nursing, 15, 833849. doi:10.1111/j.1365-2850.2008.01321.x

Klomek, A. B., Sourander, A., \& Gould, M. S. (2011). Bullying and suicide: Detection and intervention. Psychiatric Times, 28. URL (last checked 4 December 2012).

http://www.psychiatrictimes.com/print/article/10168/1795797?printa ble $=$ true

Nader, K. (2011). The assessment of associated features important to understanding childhood trauma. Journal of Child \& Adolescent Trauma, 4, 259-273. doi:10.1080/19361521.2011.614923

Penn State (2012). Exposure to violence has long-term stress effects 


\section{A. SHAVERS}

among adolescents. Science Daily. URL (last checked 4 December 2012).

http://www.sciencedaily.com/releases/2012/07/120703162630.htm

Pinheiro, P. S. (2006). World report on violence against children. Geneva: United Nations.

Schwarz, S. W. (2009). Adolescent mental health in the United States: Facts for policymakers. New York: National Center for Children in Poverty (NCCP) Mailman School of Public Health Columbia University.

Shavers, C. A. (2009). (Commentary). Minimize the impact of violence for youth. The Clinical Advisor: A Forum for Nurse Practitioners, 74

Shavers, C. A. (2010). (Point of View). Promoting the health of children and adolescents exposed to trauma and violence. Primary Issues $^{\mathrm{TM}}$. URL (last checked 9 February 2013).

http://www.primaryissues.org/2010/09/

Shavers, C. A., Levendosky, A. A., Dubay, S. M., Basu, A., \& Jenei, J. (2005b). Domestic violence research: Methodological issues related to a community-based intervention with a vulnerable population. Journal of Applied Biobehavioral Research, 10, 27-38. doi:10.1111/j.1751-9861.2005.tb00002.x

Shavers, C. A., Levendosky, A. A., Dubay, S. M., Basu, A., Malone, J., Thomas, B., \& Rostant, O. S. (2005a). Child witnesses of domestic violence: Suffering in silence (unpublished manuscript).

Task Force on Community Preventive Services (2008). Recommendations to reduce psychological harm from traumatic events among children and adolescents. American Journal of Preventive Medicine, 35, 314-316. doi:10.1016/j.amepre.2008.06.025

Turner, H. A., Finkelhor, D., Shattuck, A., \& Hamby, S. (2012). Recent victimization exposure and suicidal ideation in adolescents. Archive of Pediatric Adolescent Medicine (in press), E1-E6. URL (last checked 29 November 2012). http://archpedi.jamanetwork.com/

Vernberg, E. M., Nelson, T. D., Fonagy, P., \& Twemlow, S. W. (2011). Victimization, aggression, and visits to the school nurse for somatic complaints, illnesses, and physical injuries. Pediatrics, 127, 842-848. doi:10.1542/peds.2009-3415

World Health Organization (2009). Violence prevention: The evidence. Geneva: World Health Organization. 